\title{
EVALUATION OF SEQUENTIAL SERUM INTERLEUKIN-6 LEVELS IN LIVER ALLOGRAFT RECIPIENTS
}

\author{
Yoshiaki Kita, Yuichi Iwaki, Anthony J. Demetris, and Thomas E. Starzl ${ }^{1}$ \\ Department of Surgery, University of Pittsburgh, Pittsburgh, Pennsylvania 15213
}

\begin{abstract}
Control serum levels of IL-6 measured by ELISA in 30 healthy blood donors or volunteers were $18 \pm \mathrm{S} 4 \mathrm{pg} / \mathrm{ml}$ (mean $\pm \mathrm{SD}$ ). Pretransplant serum levels of IL-6 in 169 adult candidates for liver transplantation were significantly higher than control in those with fulminant hepatitis $(203 \pm 232$ $\mathrm{pg} / \mathrm{ml})$, alcoholic cirrhosis $(116 \pm 257 \mathrm{pg} / \mathrm{ml})$, and hepatocellular carcinoma $(82 \pm 105 \mathrm{pg} / \mathrm{ml})$. With these data as background, plasma or serum levels of EL-6 were monitored in 24 adult patients after first OLT and correlated with the clinical courses and the histopathological diagnosis of rejection. Serum or plasma levels of IL-6 decreased after transplantation regardless of pretransplant value. Four patients with infection subsequently developed continuously high IL-6 values. In the 20 of 24 patients who did not have infection, significantly higher levels of IL-6 were consistently found $0-4$ days before histopathological diagnosis of rejection $(131 \pm 78 \mathrm{pg} / \mathrm{ml})$ compared with significantly lower values in patients without rejection episodes $(40 \pm 21 \mathrm{pg} / \mathrm{ml})$. The elevations of IL-6 were spike shaped, did not correlate well with the histopathological grades of rejection, and were highly responsive to augmented immunosuppression. These 20 cases were classified as: group 1, no spikes of IL-6 after liver transplantation; group 2, single spike of IL-6 after liver transplantation; and group 3, multiple spikes of IL-6 after liver transplantation. The combined early and late graft loss of each group was 0\% (group 1), 25\% (group 2), and 67\% (group 3). We conclude that daily monitored serum or plasma IL-6 levels can be a good premonitor of liver allograft rejection and also a useful predictor of long-term graft outcome.
\end{abstract}

The diagnosis of liver allograft rejection is based largely on liver function tests. Although they can assess the graft damage associated with rejection, histopathological findings have been the gold standard. Markers of immune activation and mediators of inflammation, such as IL-2, soluble IL-2R (sIL-2R), ${ }^{*}$ and TNF- $\alpha$ could provide noninvasive methods of diagnosis of rejection. IL-6 is an immunoregulator of cell growth and differentiation that is produced mainly by human monocytes/macrophages, fibroblasts, endothelial cells, and activated T cells (1). IL-6 is one of the principal mediators of inflammation (2) and an inducer of the hepatic synthesis of the majority of acute phase proteins $(3,4)$. Because the liver is a major target organ for IL-6 (5), and because allograft rejection is fundamentally an inflammatory response, we prospectively studied the relationship of serum or plasma IL-6 after liver transplantation and liver allograft rejection.

Copyright $\odot 1994$ by Williams \& Wilkins

${ }^{1}$ Address correspondence to: Dr. T. Starzl, Department of Surgery, University of Pittsburgh, 3601 Fifth Avenue, Pittsburgh, PA 15213.

*Abbreviations: POD, postoperative day; sIL-2R, soluble IL-2R. 


\section{MATERIALS AND METHODS}

\section{Healthy volunteers}

IL-6 was measured in 30 randomly selected blood donors and healthy laboratory personnel.

\section{Liver transplant candidates}

Preoperative IL-6 was measured in 169 consecutive infection-free candidates for first OLT or abdominal organ cluster transplantation between March 1988 and November 1990 at the Presbyterian-University Hospital of Pittsburgh, University of Pittsburgh, Pittsburgh, PA. The age, sex, and original disease distribution are listed in Table 1.

\section{Liver transplant recipients}

Twenty-four adult patients ( 15 males and 9 females, mean age 49.3 years, range 28-64 years) who actually underwent first OLT were selected randomly for pre- and postoperative IL-6 studies between November 1989 and March 1990. The indications for OLT were chronic active hepatitis in 3, cirrhosis in 19, and malignancy in 2 (Table 2). The mean follow-up for IL-6 measurement was 26 days (range 13-48 days).

\section{Immunosuppression}

Baseline immunosuppression was with FK506 $(n=22)$ or CsA $(n=2)$, to which variable doses of methylprednisolone were added; OKT3 was given when indicated. One CsA-treated patient was switched to FK506 because of CsA-resistant rejection.

\section{Diagnosis and treatment of rejection}

Episodes of rejection suspected on clinical grounds were confirmed by histopathological findings of biopsy specimens. Grading of acute cellular rejection was by one of us (A.J.D.). Initial treatment of rejection was with intravenous methylprednisolone (steroid bolus). Patients failing to respond were given high-dose steroid recycle over 5 days, or OKT3 was instituted.

\section{Samples}

Blood samples were separated to serum (all candidates, 169 samples; 8 OLT recipients, 123 samples) or plasma (16 OLT recipients, 284 samples). The blood samples were maintained at $4{ }^{\circ} \mathrm{C}$ during preparation, and the serum or plasma stored at $-20^{\circ} \mathrm{C}$. The postoperative samples were collected daily, except on weekends. In patients suspected of rejection, samples were always taken on the day of biopsy, and the 2 succeeding days. In most of these cases, samples were available for the preceding 4 days.

\section{IL-6 Assay}

ELISA was performed by two-step sandwich enzyme immunoassay method using a commercially available ELISA kit (Quantikine human IL-6 immunoassay, Research and Diagnostic Systems, Inc., Minneapolis, MN), according to the manufacturer's instructions. Briefly, $50 \mu 1$ of assay buffer (buffered protein base) were added to 96-well microplates coated with mouse anti-human IL-6 mAb (first antibody). Then, $200 \mu \mathrm{l}$ of test samples were added to microplates. After 2-hr incubation at room temperature, the wells were washed, $200 \mu 1$ of horseradish peroxidase-conjugated goat anti-human IL-6 polyclonal antibody were added, and incubation was carried out at room temperature for $2 \mathrm{hr}$. The wells were washed as above and incubated at room temperature for $20 \mathrm{~min}$ with chromogen, which was a mixture of $\mathrm{H}_{2} \mathrm{O}_{2}$ and tetramethylbenzidine. After a last incubation, $50 \mu \mathrm{l}$ of $2 \mathrm{~N} \mathrm{H}_{2} \mathrm{SO}_{4}$ were added to stop the reaction and optical density at $450 \mathrm{~nm}$ was measured using a microtiter 
reader (Titertek Multiskan, Flow Laboratories, Inc., McClean, VA). The standard curve for IL-6 ranging from $31.3 \mathrm{pg} / \mathrm{ml}$ to $2000 \mathrm{pg} / \mathrm{ml}$ was drawn by $\log / \log$ scale. IL-6 values of the samples were calculated by this standard curve. Assay sensitivity was $10 \mathrm{pg} / \mathrm{ml}$.

\section{Statistical analysis}

Difference in IL-6 levels between each candidate group were analyzed by Student's $t$ tests. Serum and plasma peak levels of IL-6 after OLT were determined as mean \pm SD. A $P$-value of less than 0.01 was considered significant.

\section{RESULTS \\ Healthy volunteers}

The normal mean value of IL-6 from 30 healthy volunteers was $18 \pm 34 \mathrm{pg} / \mathrm{ml}$ (range $0-158$ $\mathrm{pg} / \mathrm{ml})$. Twenty-one $(70 \%)$ had nondetectable $(<10 \mathrm{pg} / \mathrm{ml})$ levels. We defined the normal IL- 6 cutoff level as $86 \mathrm{pg} / \mathrm{ml}$, which was the mean $\pm 2 \mathrm{SD}$ value of the 30 healthy volunteers. Two (7\%) of the 30 had IL-6 levels greater than $86 \mathrm{pg} / \mathrm{ml}$.

\section{Correlation between serum and plasma levels of IL- 6}

A high degree of correlation was found between serum and plasma levels of IL-6 from 10 same blood samples $(r=0.991)$.

\section{Serum levels of IL-6 in 169 liver transplant candidates}

Elevated serum levels greater than the cutoff value of $86 \mathrm{pg} / \mathrm{ml}$ were observed in the patients with fulminant hepatitis (50\%; mean $203 \pm 232 \mathrm{pg} / \mathrm{ml}$ ) alcoholic cirrhosis (24\%; mean $116 \pm 257 \mathrm{pg} / \mathrm{ml}$ ), and hepatocellular carcinoma (33\%; mean $82 \pm 105 \mathrm{pg} / \mathrm{ml})$. Candidates with other diseases had IL-6 within the 2 SD range (Table 1).

\section{IL-6 monitoring of 24 liver transplant recipients}

The 24 patients studied postoperatively had a total of 28 liver transplants: 3 required retransplantation because of primary non-function $(n=2)$ or rejection $(n=1)$ and 1 required a third transplantation because of persistent rejection. The shortest hospital course was 13 days and the longest course was 8 months. The latter patient died of sepsis and multiple systems organ failure. A total of 407 (123 serum and 284 plasma) samples were analyzed for IL- 6 concentration over the average monitoring period of 26 days (range 13-48 days). In the patients without infection and with stable well-functioning grafts, serum or plasma IL-6 levels remained within normal range no matter what the pretransplant values (Fig. 1). Four patients suffering from bacterial infection had persistently increased IL-6 levels during these episodes to as high as or higher than $1000 \mathrm{pg} / \mathrm{ml}$.

With acute cellular rejection in the 20 uninfected patients, IL- 6 was increased from 0 to 4 days before the histopathological diagnosis of rejection. These elevations occurred in spikes, and always fell rapidly within $48 \mathrm{hr}$ after the institution of antirejection therapy whether this was successful or not. However, when rejection was not controlled or recurred, IL-6 levels increased again. A total of 29 biopsies were done in these 20 recipients during the IL- 6 monitoring period. Twenty-one of the biopsies had unequivocal evidence of acute cellular rejection, whereas 8 had equivocal or no evidence of rejection. With a histopathological diagnosis of rejection, the mean peak values of IL-6 levels were $131 \pm 78$, and without this diagnosis the values were $40 \pm 21(P<0.01)$. A mean peak value of serum IL-6 levels was greater than $86 \mathrm{pg} / \mathrm{nil}$ in $76 \%$ of the rejection group and $0 \%$ in the nonrejection group $(P<$ $0.01)$. 
In the uninfected patients with acute cellular rejection, there was not a clear correlation between IL-6 peak values and histopathological grades of rejection, nor was there a correlation between IL-6 levels and white blood cell count, total bilirubin, serum glutamic oxaloacetic transaminase, serum glutamic pyruvic transaminase, alkaline phosphatase, and $\gamma$-GTP levels. Rather, the correlation appeared to be between the outcome and number of IL-6 spikes (Table 3). However, when these 20 patients were classified according to the numbers of IL-6 spikes as group 1 (no spike), group 2 (single spike), and (3) group 3 (multiple spikes), those of group 3 suffered severer histopathological rejection and a higher mortality.

IL-6 levels from 4 representative patients ( 3 uninfected and 1 infected) are plotted in Figure 2. Figure $2 \mathrm{~A}$ shows a normal IL-6 profile of a patient who had an uneventful postoperative course. The patient in Figure 2B had a moderate rejection with an IL-6 spike on the sixth postoperative day (POD), a biopsy showing rejection on POD 7, and successful treatment with steroids on POD 8.

The course in Figure $2 \mathrm{C}$ is from a patient with early ischemic injury and later severe acute cellular rejection. Postoperatively, IL-6 levels were low on POD 5, at which time the biopsy showed ischemic damage. The markedly increased early postoperative bilirubin levels gradually fell until the diagnosis of mild acute cellular rejection was made on POD 21. Two days before this diagnosis, IL-6 levels increased slightly. Eight days later, severe acute cellular rejection was diagnosed by biopsy, at which time there was an IL-6 spike that resolved with OKT3 treatment. Figure 2D shows the IL-6 values of a patient with necrotizing fasciitis and abdominal abscesses from the second postoperative week. IL-6 levels rose steadily to astronomical levels.

\section{DISCUSSION}

Recently, measurements of plasma, serum, urine; or bile cytokine levels have been reported as indicators of the early diagnosis of rejection. Products of activated T lymphocytes, such as IL-2 or soluble components of its receptor (sIL-2R), have been particularly well studied. Perkins et al. (6) and Adams et al. (7) reported the efficacy of sIL-2R in serum and bile as an indicator of liver allograft rejection, but these measures have not been widely applied. The monocyte/macrophage-derived cytokines, TNF- $\alpha$, and IL-6 are released in relatively large amounts early in the immune activation process and can be detected readily in the circulation by a sensitive ELISA assay. Imagawa et al. (8) described elevated serum TNF- $\alpha$ values as predictive of human liver allograft rejection and, in rats, Tono et al. (9) observed that bile IL-6 levels correlated with the severity of rejection. Van Oers et al. (10) and Yoshimura et al. (11) reported the efficacy of IL-6 for diagnosing renal allograft rejection.

In our study, it was observed that the pretransplant IL-6 value depended upon the nature of the original liver disease. Preoperative elevations were common with fulminant hepatic failure, alcoholic cirrhosis, and neoplastic disease. In fulminant hepatic failure, or with endstage chronic failure, sepsis and endotoxemia and/or impairment of liver reticuloendothelial system function are common (12). This reticuloendothelial system function impairment allows a variety of gut-derived antigens to be released into the general circulation, presumably with IL- 6 production. Muto et al. (13) reported that TNF- $\alpha$ production was increased and correlated closely with activity of IL-1. IL-6 is also a monokine produced by monocytes/macrophages in response to infection and endotoxin. Alcohol increases the permeability of gastrointestinal mucosa, and could result in increased absorption of macromolecules, such as dietary or bacterial proteins, into the general circulation. Alcohol also impairs Kupffer cell phagocytic function, theoretically predisposing to excessive production of IL-6 with alcoholic cirrhosis. Deviere et al. $(14,15)$ have reported increased 
serum levels of IL-6 and in vitro spontaneous or Induced excessive production of IL-6 by PBMC of alcoholic cirrhosis patients.

In patients with hepatocellular carcinoma, elevated serum IL-6 levels also have been reported, which is not surprising because IL-6 is a common participant in the host-tumor interaction (16). Increased erythrocyte sedimentation rate, increased serum levels of acute phase proteins, decrease in serum albumin, and fever are common systemic features in tumor-bearing hosts. These features are strongly associated with the function of IL-6. Tabibzadeh et al. (17) reported the distribution of IL-6 immunoreactivity in different human tumors using an immunohistochemical technique, leaving unresolved the question of whether neoplastic cells secrete IL-6 or merely accumulate it. However, elevated IL-6 levels in circulation have been observed in patients with neoplastic diseases (18), and Matsuguchi et al. (19) observed production of IL-6 from human liver cell lines.

No matter what the pretransplant value, our studies suggest that IL-6 levels in the absence of infection are initially normalized with successful OLT. These observations are potentially at variance with those of Fugger et al. (20), who reported that intraoperative endotoxin, TNF- $\alpha$, and IL-6 were closely (and presumably causally) related to postoperative rejection and infection; such an association of preoperative endotoxin and postoperative morbidity also has been reported in our earlier cases by Yokoyama et al. (12) and Miyata et al. (21). The normalization in our patients was interrupted by rejection.

Rejecting liver allografts are characterized by a cellular infiltration consisting mainly of monocytes/macrophages and T lymphocytes, all of which may secrete IL-6. In addition, liver Kupffer cells and vascular endothelial cells also secrete IL-6. Therefore, infiltrating host immune cells or cells of the allograft could have a role in producing IL-6. In addition, the liver is the major target organ of IL-6 (5). In a counterregulatory process, IL-6 stimulates pituitary cells to release adrenocorticotrophic hormone, and subsequently result in the synthesis of corticosteroids (22). The systemic glucocorticosteroids inhibit production of IL-6. The data herein reported have suggested a possibility of IL-6 regulation by steroid treatment inasmuch as IL-6 levels fell within $48 \mathrm{hr}$ of bolus steroid therapy, whether or not rejection was brought under control.

The direct influence of other immunosuppressive drugs on IL- 6 can only be speculated upon. CsA and FK506 are thought not to inhibit IL-6 production in vitro (23). Anti-CD3 murine mAb (OKT3) actually raises IL-6 levels in transplant recipients $(24,25)$. However, in our study, even in the patient treated with OKT3, we could not observe an increase of IL-6. IL-6 spikes always appeared at the time of first rejection episode, or with recurrence of rejection. These observations suggest that the rejection (or alternatively infection), rather than the drugs used for treatment, was the dominant factor in the determination of IL-6 levels.

In clinical application, the IL-6 rises due to rejection, whereas increases caused by infection appear to be distinguishable. With bacterial infection, serum IL-6 levels were unrelentingly elevated, usually to extraordinary heights $(>1000 \mathrm{pg} / \mathrm{ml})$. This pattern contrasted with the spikes of IL-6 seen with rejection that were quickly responsive to intensification of immunosuppression. The need for serial testing can be met with current technology. The IL-6 ELISA assay takes less than $5 \mathrm{hr}$.

\section{REFERENCES}

1. Kishimoto T. The biology of interleukin-6. Blood 1989;74:1. [PubMed: 2473791]

2. Van Snick J. Interleukin-G: an overview. Annu Rev Immunol 1990;8:253. [PubMed: 2188664] 
3. Heinrich PC, Castell JV, Andus T. Interleukin-6 and acute phase. Biochem J 1990;265:621. [PubMed: 1689567]

4. Fey, GH.; Gauldie, J. The acute phase response of the liver inflammation. In: Popper, H.; Schaffner, F., editors. Progress in liver disease. Vol. Vol 9. Philadelphia: WB Saunders; 1990. p. 89

5. Castell JV, Geiger T, Gross V, et al. Plasma clearance, organ distribution and target cells of interleukin 6/hepatocyte-stimulating factor in the rat. Eur J Biochem 1988;177:357. [PubMed: 3263918]

6. Perkins JD, Nelson DL, Grambsch PJ, Krom RAF. Soluble interleukin 2 receptor level as an indicator of liver allograft rejection. Transplantation 1989;47:77. [PubMed: 2536202]

7. Adams DH, Wang L, Hubscher SG, Elias E, Neuberger JM. Soluble interleukin-2 receptor in serum and bile of liver transplant recipients. Lancet 1989;1:469. [PubMed: 2563843]

8. Imagawa DK, Millis JM, Olthoff KM, et al. The role of tumor necrosis factor in allograft rejection. Transplantation 1990;50:219. [PubMed: 2382288]

9. Tono T, Monden M, Yoshizaki K, et al. Biliary interleukin 6 levels as indicators of hepatic allograft rejection in rats. Transplantation 1992;53:1195. [PubMed: 1604472]

10. Van Oers MHJ, Van Der Heyden AAPAM, Aarden LA. Interleukin-6 (IL-6) in serum and urine of renal transplant recipients. Clin Exp Immunol 1988;71:314. [PubMed: 3280187]

11. Yoshimura N, Oka T, Kahari BD. Sequential determinations of serum interleukin 6 levels as an immunodiagnostic tool to differentiate rejection from nephrotoxicity in renal allograft recipients. Transplantation 1991;51:172. [PubMed: 1987687]

12. Yokoyama I, Todo S, Miyata T, Selby R, Tzakis AG, Starzl TE. Endotoxemia and human liver transplantation. Transplant Proc 1989;21:3833. [PubMed: 2510378]

13. Muto Y, Nousi-Aria KT, Meager A, Alexander GJM, Eddleston ALWF, Williams R. Enhanced tumor necrosis factor and interleukin-1 in fulminant hepatic failure. Lancet 1988;2:72. [PubMed: 2898700]

14. Deviere J, Content J, Denys C, et al. Excessive in vitro lipopolysaccharide-induced production of monokines in cirrhosis. Hepatology 1990;11:628. [PubMed: 2184115]

15. Deviere J, Content J, Denys C, et al. High interleukin-6 levels and increased production by leukocytes in alcoholic liver cirrhosis. Correction with IgA serum levels and lymphokines production. Clin Exp Immunol 1989;77:221. [PubMed: 2505958]

16. Sehgal PB. Interleukin 6 in infection and cancer. Proc Soc Exp Biol Med 1990;195:183. [PubMed: 2236101]

17. Tabibzadeh SS, Poubouridis D, May LT, Sehgal PB. Interleukin-6 immunoreactivity in human tumors. Am J Pathol 1989;135:427. [PubMed: 2675620]

18. Featon KCH, McMillan DC, Preston T, Wisnstanley FP, Cruickshank AM, Shenkin A. Elevated circulating interleukin-6 is associated with an acute-phase response but reduced fixed hepatic protein synthesis in patient with cancer. Ann Surg 1991;213:26. [PubMed: 1898691]

19. Matsuguchi T, Okamura S, Kawasaki S, Niho Y. Production of interleukin 6 from liver cell lines: production of interleukin 6 is not concurrent with the production of $\alpha$-fetoprotein. Cancer Res 1990;50:7457. [PubMed: 1701344]

20. Fugger R, Hamilton G, Steininger R, Mirza D, Schulz F, Muhlbacher F. Intraoperative estimation of endotoxin, TNF- $\alpha$, and IL-6. in orthotopic liver transplantation and their relation to rejection and operative infection. Transplantation 1991;52:302. [PubMed: 1871803]

21. Miyata T, Yokoyama I, Todo S, Tzakis A, Selby R, Starzl TE. Endotoxaemia, pulmonary complications, and thrombocytopenia in liver transplantation. Lancet 1989;2:189. [PubMed: 2568522]

22. Woloski BMRNJ, Smith EM, Meyer WJ III, Fuller GM, Blalock JE. Corticotropin-releasing activity of monokines. Science 1985;230:1035. [PubMed: 2997929]

23. Yoshimura N, Matsui S, Hamashima T, Oka T. Effect of a new immunosuppressive agent, FK506, on human lymphocyte responses in vitro. Transplantation 1989;47:356. [PubMed: 2465593]

24. Bloemena E, Ten Berge IJM, Surachno J, Wilmink JM. Kinetics of interleukin 6 during OKT3 treatment in renal allograft recipients. Transplantation 1990;50:330. [PubMed: 2143327] 
25. Abramowicz D, Schandene L, Goldman M, et al. Release of tumor necrosis factor, interleukin-2, and $\gamma$-interferon in serum after injection of OKT3 monoclonal antibody in kidney transplant recipients. Transplantation 1989;47:606. [PubMed: 2523100] 


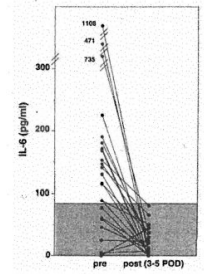

Figure 1.

Serum IL-6 before and after first liver transplantation in 24 recipients. 


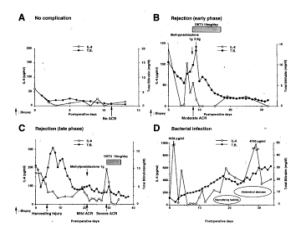

Figure 2.

Serum or plasma IL-6 monitoring in 4 representative liver transplant recipients. Arrows shows the time of biopsy or drug administration. (A) Group 1: case EM, alcoholic cirrhosis and hepatocellular carcinoma, 64-year-old man; (B) group 2: case EF, cryptogenic cirrhosis, 61-year-old woman; (C) group 3: case DM, cryptogenic cirrhosis, 48-year-old man; (D) group 4: case TM, postnecrotic cirrhosis due to hepatitis B, 56-year-old man. 


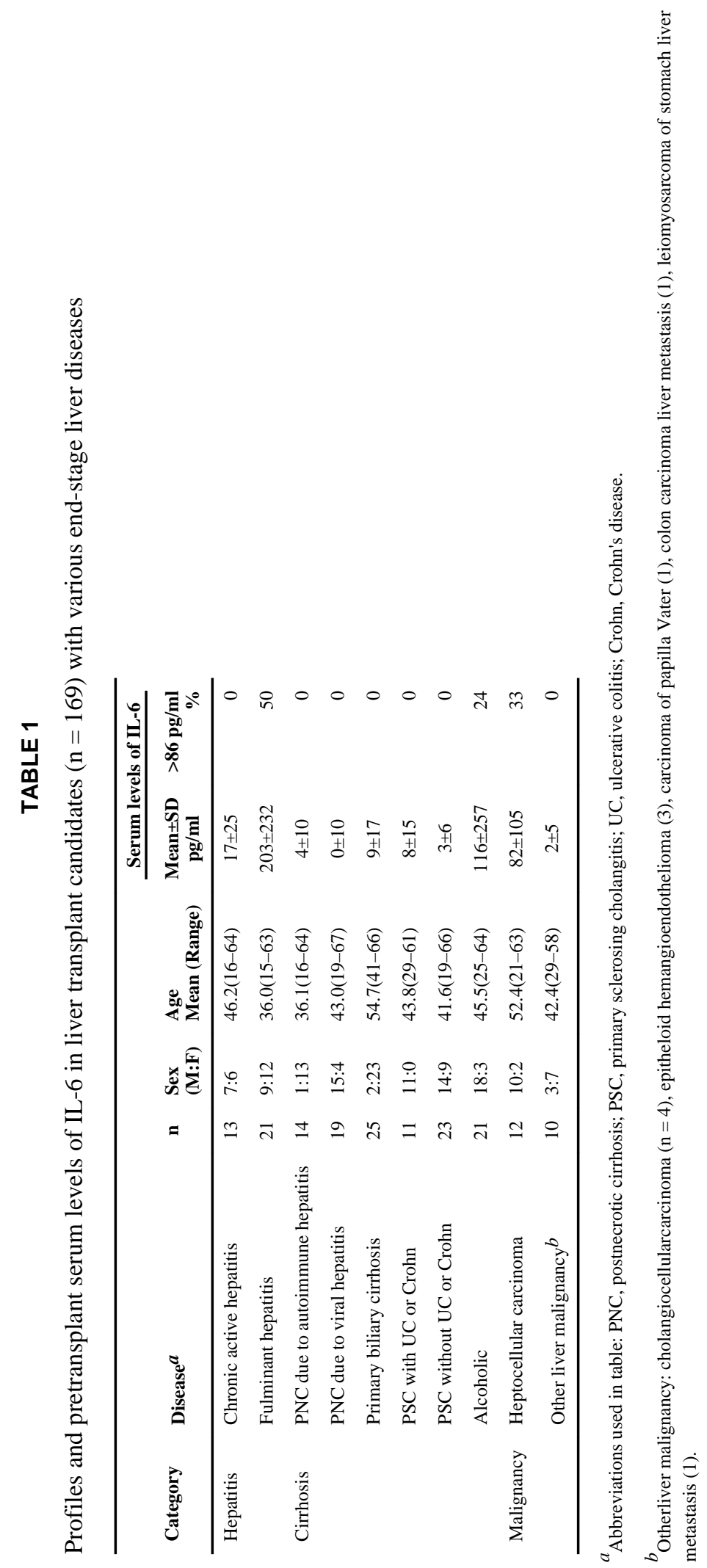

Transplantation. Author manuscript; available in PMC 2011 January 18. 
TABLE 2

Profiles of liver transplant recipients who underwent first liver transplantation $(n=24)$

\begin{tabular}{llccl}
\hline Category & Disease & $\mathbf{n}$ & $\begin{array}{l}\text { Sex } \\
(\mathbf{M : F})\end{array}$ & $\begin{array}{l}\text { Age } \\
\text { Mean (Range) }\end{array}$ \\
\hline Hepatitis & Chronic active hepatitis & 3 & $1: 2$ & $40.3(28-59)$ \\
Cirrhosis & PNC due to autoimmune hepatitis & 1 & $1: 0$ & $58(58)$ \\
& PNC due to viral hepatitis & 7 & $3: 4$ & $44.1(33-61)$ \\
& Alcoholic & 10 & $7: 3$ & $50.3(37-64)$ \\
& $\mathrm{SBC}^{a}$ due to biliary atresia & 1 & $1: 0$ & $34(34)$ \\
Malignancy & $\mathrm{Hepatocellular} \mathrm{carcinoma}^{b}$ & 2 & $2: 0$ & $57.5(51-64)$ \\
\hline
\end{tabular}

${ }^{a}$ Abbreviations used in table: PNC, postnecrotic cirrhosis; SBC, secondary biliary cirrhosis.

${ }^{b}$ Hepatocellular carcinoma; hepatocellular carcinoma with PNC due to viral hepatitis $(\mathrm{n}=1)$, hepatocellular carcinoma with alcoholic cirrhosis (1). 
TABLE 3

Relation of serum or plasma IL-6 levels to histopathological diagnosis of rejection and eventual mortality in liver transplant recipients $(n=24)$

\begin{tabular}{|c|c|c|c|c|}
\hline Group & $\mathbf{n}$ & Pathological diagnosis & & Mortality \\
\hline \multirow{4}{*}{$\begin{array}{l}\text { No 1L-6 spike } \\
\text { (group 1) }\end{array}$} & \multirow{4}{*}{6} & No $\mathrm{ACR}^{a}$ & 4 & \multirow{4}{*}{$0 / 6(0 \%)$} \\
\hline & & Minimal-mild ACR & 2 & \\
\hline & & Moderate-severe ACR & 0 & \\
\hline & & No ACR & 3 & \\
\hline \multirow{3}{*}{$\begin{array}{l}\text { Single IL-6 spike } \\
\text { (group 2) }\end{array}$} & \multirow[t]{3}{*}{8} & Minimal-mild ACR & 1 & \multirow[t]{3}{*}{$2 / 8(25 \%)$} \\
\hline & & Moderate-severe ACR & 4 & \\
\hline & & No ACR & 0 & \\
\hline \multirow{3}{*}{$\begin{array}{l}\text { Multiple IL-6 spikes } \\
\text { (group 3) }\end{array}$} & \multirow[t]{3}{*}{6} & Minimal-mild ACR & 1 & \multirow[t]{3}{*}{$4 / 6(67 \%)$} \\
\hline & & Moderate-severe ACR & 5 & \\
\hline & & No ACR & 2 & \\
\hline \multirow{2}{*}{$\begin{array}{l}\text { Continuously high IL-6 } \\
\text { (group 4) }\end{array}$} & \multirow[t]{2}{*}{4} & Minimal-mild ACR & 2 & \multirow[t]{2}{*}{$4 / 4(100 \%)$} \\
\hline & & Moderate-severe ACR & 0 & \\
\hline
\end{tabular}

